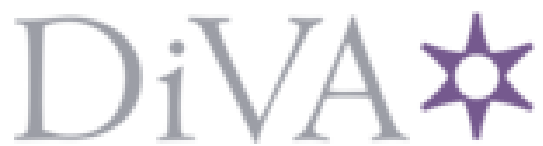

http://www.diva-portal.org

This is the published version of a paper published in Acta Sociologica.

Citation for the original published paper (version of record):

Fürst, H. (2018)

Aspiring Writers and Appraisal Devices under Market Uncertainty

Acta Sociologica, 61(4): 389-401

https://doi.org/10.1177/o001699317749285

Access to the published version may require subscription.

N.B. When citing this work, cite the original published paper.

Permanent link to this version:

http://urn.kb.se/resolve?urn=urn:nbn:se:uu:diva-312274 


\title{
Aspiring writers and appraisal devices under market uncertainty
}

(c) The Author(s) 2018

Reprints and permissions: sagepub.co.uk/journalsPermissions.nav DOI: $10.1177 / 0001699317749285$ journals.sagepub.com/home/asj

(SAGE

\section{Henrik Fürst}

Department of Sociology, Mälardalen University, Västerås, Sweden

\begin{abstract}
Aspiring artists are uncertain about how their work's quality will be evaluated by gatekeepers on artistic markets. Learning to evaluate the quality of one's work and its prospects on the artistic market is central to artistic careers, yet often overlooked in research. An analysis of 47 interviews with aspiring writers in Sweden shows that they use what in this article is coined appraisal devices to deal with this market uncertainty. Appraisal devices offer trusted and knowledgeable appraisals of their work's chances of success and failure on the artistic market. Appraisals from assessors become appraisal devices when assessors are trusted and seen as knowledgeable about how works are evaluated on the artistic market and are able to produce such evaluations. Appraisals from competitions become appraisal devices when the writer sees the evaluation as reflecting how the writer's work will be evaluated on the artistic market. In contrast to judgment devices, which take the perspective of cultural consumption, appraisal devices take the perspective of cultural production. Aspiring artists use appraisal devices to deal with the uncertainty of their chances of success on the artistic market.
\end{abstract}

\section{Keywords}

Appraisal device, judgment device, quality uncertainty, aspiration, assessor, competition, literary career, cultural production

\section{Introduction}

Aspiring artists are uncertain about how the quality of their creative work will be evaluated by gatekeepers to artistic markets. For fiction writers, this uncertainty exists because of the general lack of objective evaluative standards for evaluating the quality of fiction (Anheier and Gerhards, 1991: 812-813; Menger, 2014: 4). Aspiring writers trying to publish their first book often do not know how publishing houses evaluate the quality of manuscripts and so face uncertainty about whether their own creative work is of the 'right' quality to be selected. 
The article asks how writers deal with the tension between their aspiration to be published for the first time and their uncertainty over whether their work is of the right quality to be selected in a publishing market. The publishing market entails a two-sided matching process between writers as sellers of cultural goods and gatekeepers, in the form of publishers, as potential buyers of cultural goods. The article aims to provide a conceptual understanding of how artists handle the tension between their own aspirations and market uncertainty. This tension is important to study as it is central throughout cultural industries, since aspirations to succeed on artistic markets are abundant and quality uncertainty is a defining characteristic of cultural industries (Caves, 2000: 6-7), artistic markets, and artistic careers (Menger, 2014: 4). To conceptually understand uncertainty and aspiration in these situations brings new light to the workings of cultural industries.

These situations of uncertainty are novel, prone to change, or shaped by a crisis, making it difficult to calculate the probability of a particular outcome, while in situations of risk it is possible to make such calculations (Knight, 1921). Hence, aspiring writers are unable to determine their own chances of success and risks of failure in their efforts to be selected. Akerlof (1970) elaborates on this type of market situation conditioned by uncertainty in the example of the market for buying used cars. There is asymmetrical information between seller and buyer: the buyer does not know the quality of the car until it is bought. As Beckert (2016) shows, when economic decision-making is conditioned by uncertainty, people need to act as if the future is more certain than it actually is, turning uncertainty into risk and thereby making the chances for success or failure calculable.

To deal with the tension between aspiration and market uncertainty, aspiring artists come to rely on what I call appraisal devices. The concept appraisal device and the associated framework are able to capture the way the market uncertainty is handled by artists aspiring to succeed in such markets. Appraisal devices reduce uncertainty about how the market will assess the quality of artists' work by creating knowledge about this quality that gives artists cognitive support in their efforts to make reasonable decisions about courses of action by turning uncertainty into risk. The concept of appraisal devices supplements sociologist Lucien Karpik's (2010) concept of judgment devices; the two concepts mirror one another; here I develop the idea of appraisal devices from Karpik's own conceptual apparatus. Appraisal devices focus on cultural production and cultural producers' perspectives on their own prospects of success or failure in an uncertain artistic market. Judgment devices focus on cultural consumption and cultural consumers' perspectives on existing cultural goods of uncertain quality on consumers markets. This extension makes it possible to understand the handling of quality uncertainty from the perspective of producers, while attaching the concept of appraisal device to a powerful theoretical framework for the analysis of quality uncertainty.

There is a general lack of knowledge about how artists themselves handle the tension between, on one hand, their aspiration to have their work selected by gatekeepers in the creative industries and, on the other hand, their uncertainty over whether their work is of the right quality to be selected. By focusing on this tension, the article advances research on uncertainty and artists in three ways. First, most research on uncertainty and artists has focused on how artists deal with economic uncertainty. For example, researchers have shown that artists use insurance devices, such as multiple jobs, to deal with economic uncertainty in their artistic careers (Lahire, 2010; Menger, 1999, 2014). Established creative artists persist under precarious working conditions because they enjoy being creative, enjoy the status awarded by their position, and have the necessary entrepreneurial skills to get new work (McRobbie, 2016). The appraisal device concept makes it possible to study the uncertainty artistic careers in a new light: to ask how aspiring artists deal with uncertainty about the quality of their work and its chances of being selected by gatekeepers on the artistic market. Second, most studies of artistic careers, and literary careers in particular, have focused on published authors (De Nooy, 1991; Ekelund and Börjesson, 2002, 2005; Janssen, 1998; Van Dijk, 1999; Van Rees and Vermunt, 1996); research usually begins with the first credit (Ekelund and Börjesson, 2002, 2005; Janssen, 1998; Van Dijk, 1999; Van Rees and Vermunt, 1996). Research on other artistic careers, such as those of actors (Zuckerman et al., 2003) and film composers (Faulkner, 1983), show the same pattern. This study makes an empirical contribution by 
focusing on the often-overlooked population of aspiring writers, who cannot use a track record of published books to handle uncertainty. Third, to fully understand artistic aspiration and uncertainty, research must take into account both success and failure. Previous research, however, has tended to focus on either successes (e.g. Ekelund and Börjesson, 2002; Janssen, 1998) or failures (e.g. Stoyanova and Grugulis, 2012). By contrast, this research includes both successes and failures throughout aspiring writers' literary careers. In sum, this article contributes to the literature on artistic careers not only by developing the concept of appraisal devices, but also by shifting perspective from economic uncertainty to artistic uncertainty and by sampling both those who have succeeded and those who have failed in their artistic career.

The shift of perspective embodied in the appraisal device concept opens up a vast area of possible new research. This article develops this concept using a case study of aspiring writers who deal with the aforementioned tension that is central throughout the cultural industries to showcase the use of the appraisal device concept in an empirical investigation. Before the case is presented, I will introduce how the concept of appraisal device relates to the literature on quality uncertainty and cultural production. The case is presented by highlighting the characteristics of trade publishing in Sweden and the methods used for collecting and analyzing the material. The conceptual apparatus is showcased by an analysis of aspiring writers handling their aspiration and the quality uncertainty in the publishing market, and the implications of the conceptual apparatus are then discussed.

\section{Quality uncertainty in cultural production}

Research on quality uncertainty and cultural production shows that cultural producers may use recurrent ties of cooperation to address quality uncertainty, as with recurrent constellations of filmmakers in film production (Faulkner and Anderson, 1987; Zuckerman et al., 2003). Other research shows that decisionmaking gatekeepers use informal strategies to manage the uncertain quality of cultural goods and cultural creators; bookers and clients, for example, use conventions about the 'right look' to choose fashion models (Mears, 2011). Consumers handle the uncertain quality of cultural goods on consumer markets by referring to networks (Cheshire and Cook, 2004; DiMaggio and Louch, 1998), the product's or producer's reputation (Beckert and Rössel, 2013), and judgment devices (Karpik, 2010).

Judgment devices are used by consumers as heuristics to determine the quality of unique and incommensurable products (Karpik, 2010: 44). A published book is an example of such a singularity. In contrast to more standardized products, as screws and nails, books are singularities, as they are perceived as unique, not easily compared, and of uncertain quality. The quality of books, or other singularities with these three defining characteristics, as music, wines, or hotels, can only be determined by using a judgment device. But judgment devices need to be both credible and trusted to successfully create knowledge about the quality of the singular product (Karpik, 2010: 55) and enable consumers to make reasonable choices about it, such as what book to buy (Karpik, 2010: 44). Consumers use five types of judgment devices - networks, appellations, cicerones, rankings, and confluences - as guideposts for learning about the singular product and determining whether it is a 'good' or 'right' product to choose. For example, consumers judge the quality of a book and make decisions about what books to buy based on what their friends buy (network), the name of the publishing house (appellations), literary critics' assessments (cicerones), bestseller lists (rankings), and how the book is presented on the shelf in the bookstore (confluence). To judge quality and make purchasing decisions, consumers may also use comparisons with exemplary goods (Dekker, 2016), such as a book's similarities to or differences from an exemplary 'good' book.

Judgment devices are about cultural consumption, but appraisal devices are about cultural production. While any evaluation can constitute an appraisal, an appraisal device is an evaluation that artists can use to handle the tension between quality uncertainty and aspiration to succeed in a market. Appraisals only become useful appraisal devices when they come from sources that are both trusted and knowledgeable enough for the artist to assume that the appraisal corresponds to how the artist's work will be evaluated 
on the artistic market. Two primary sources of appraisal devices have been identified from the empirical material. These two sources come from assessors and competitions.

Assessors are individuals who appraise the chances of success and failure of the artist's work on the artistic market - for example, literary mentors who signal to writers the chances that their work will be selected or rejected by publishers. Assessors are part of the artist's network and are seen as trusted and knowledgeable professionals who belong to what Karpik (2010: 102) has called a network-market plus professional authority regime. They become what Karpik calls personal devices, as they give writers personalized information about their work and their chances of success and failure, rather than impersonal devices producing knowledge available to a public. Assessors also produce specific knowledge about the content of the singularity and are, therefore, act as, what Karpik calls, substantial devices, in contrast to formal devices that produce knowledge by the relative position of the singularity. In estimating a work's chances for success and failure and its possible match or mismatch on the artistic market, the assessor is engaging in what I call a matching logic. In the matching logic they can imagine that the evaluation is similar to how their work would be evaluated on the market and how the work matches with the other side of this market. The writer has an active relationship to the appraisal: he or she searches for answers to questions about the chances of success or failure and also accepts the assessor's taste and evaluation.

Competitions similarly become appraisal devices when the artist sees the competition's gatekeepers as knowledgeable and trusts that their evaluation is expected to correspond to how gatekeepers for the artistic market will evaluate the submitted creative work. An example of an appraisal from a competition is the outcome of literary awards contest; this outcome becomes an appraisal device when the writer sees it as reflecting not only an evaluation of the submitted work, but also how a publishing house would evaluate unwritten future work. These devices are personal devices that give the writer personalized information, but only indirectly: competitions result in a rank order determined by experts, in what Karpik (2010: 104-105) has called an expert-opinion regime. The resulting rank order becomes a formal device bringing knowledge by the relative position of the singularity. Competitions that gain legitimacy in the field use criteria of excellence and originality, and artists assume that these criteria reflect a matching logic that corresponds to how gatekeepers for the artistic market would evaluate their work. Here, again, artists are active in their search for knowledge and come to trust the tastes and evaluations demonstrated in the competition.

\section{Research material and methods}

The research for this article was carried out in Sweden, where, in a nationally representative sample, about 20 percent of respondents stated that they would like to become a published fiction author (Cint, 2010). Moreover, just as in other countries, such as the UK (Dahlgreen, 2015), one of the most soughtafter occupations in Sweden is that of author (Kairos Future, 2013). While many people dream about becoming published, only some pursue their aspiration to become published and submit a manuscript to a publishing house. The largest publishing houses in Sweden receive around 1000 to 3000 fiction manuscripts per year, and smaller publishing houses receive around 50 manuscripts per year. But only a handful of these manuscripts become debut novels. As in the other Nordic countries, aspiring writers in Sweden usually send unsolicited manuscripts directly to publishing houses or submit manuscripts through a network of contacts. It is uncommon in Sweden for aspiring writers' manuscripts to be acquired by literary agencies before being sold to publishing houses. This situation differs from the publishing industry in, for example, the US and the UK (Thompson, 2012: 71-74), where literary agencies have a more influential role in selling aspiring writers' manuscripts to publishing houses.

This study's sampling strategy was designed to bring as much variation as possible into the material by including writers in different positions and with different experiences in relation to getting published. I interviewed writers who were currently aspiring to be published, writers whose work had been published, and writers who had never been published and had given up on that aspiration. All writers 
were interviewed about being or having been aspiring writers. To effectively build a sampling frame of published authors, I constructed a database of fiction debuts between 1997 and 2014. I conducted a descriptive analysis of the database to determine authors' ages, genders, locations, years of publication, book titles, publishing houses, types of book, genres, literary prize nominations and awards, and writing school participation. Based on this descriptive analysis, I sampled writers who had published their work within the previous five years with the aim of interviewing as wide a variety of writers as possible. For example, in addition to interviewing writers who lived near the cultural center of Stockholm, I interviewed writers in four other large cities in Sweden: Göteborg, Malmö, Umeå, and Uppsala. Writers who had not become published at the time of the interview were harder to sample, since they had often not made their aspirations public. I located these authors through recommendations from writers I had already interviewed, through meetings during literary events, through writing schools, and through writing groups, all with the aim of introducing as much variation as possible into the networks and contexts used for sampling.

The sampling procedure resulted in 47 interviews, which I conducted in 2013 and 2014. Out of these interviews, 43 were with individual writers, and four were group interviews. I conducted three group interviews at two writing schools and one group interview with members of a writing group. The group interviews were initially a sampling strategy to get access to unpublished authors. These interviews also produced material on the role of writing schools in assessing one's chances for success or failure in becoming published. Including both the individual interviewees and the group interview participants, I interviewed a total of 58 fiction writers: 33 of these were published authors and 25 were unpublished authors; 21 were men and 37 were women; and their ages ranged from 20 to 70 . The interviews usually lasted about one to two hours, resulting in roughly 60 hours of recorded material and 790 pages of transcribed text. Excerpts from this transcript illustrate the analysis below.

To understand the tension between aspiration and market uncertainty, I studied the objective and subjective sides of these writers' literary careers. An objective career is 'a stream of more or less identifiable positions, offices, status, and situations that served as landmarks for gauging a person's movement through the social milieu' (Barley, 1989: 49). The subjective side consists of 'the meanings individuals attributed to their career, the sense they made of their becoming' (Barley, 1989: 49). To learn about writers' objective literary careers points and their subjective experiences of those career points, I presented them with a 'career scheme template' one-third of the way into each interview, after devoting the first third of the interview to open-ended questions. I developed this template during the study's first open-ended interviews; it quickly became saturated in the following interviews. The template features different literary activities or identifiable positions in their career, such as 'writing projects', 'publications', 'selections/rejections', 'writing course', 'writing school', 'other' (e.g. having or being a literary mentor, being a jury member for a literary prize, etc.), and a chronological time scale. The writers could then insert different literary activities in which that they had participated, were participating, and planned to participate. I then asked them to say more about these literary activities and also reflect on omissions. The scheme represented the writer's objective literary career. How the writers talked about their objective literary career represented their subjective experience of their career. Writers' evaluations of the objective side of their literary careers became meaningful and sometimes came to be talked about as appraisal devices; for example, some writers talked about using acceptance into a writing school as an appraisal device.

Using retrospective interviews to study life courses runs the risk of creating an illusory coherence and directedness in participants' lives (Bourdieu, 2000) and may fail to explain action due to such interviews' inability to access non-discursive cognitive processes (Martin, 2010; Vaisey, 2009). Interpreting interviews may, however, give access to persons' discursive knowledge and, while not explaining action, at least outline the schemas that can guide action (Lamont and Swidler, 2014; Pugh, 2013). This study uses interviews to understand how participants get knowledge about the quality of their work on the publishing market; writers describe using a schema of appraisal devices to draw boundaries between different types and sources of information about quality. 
I transcribed the collected interview material and indexed in codes and categories in a first cycle of coding; these codes were related to how a writer becomes a first-time author. I then selected bundles of these first-cycle codes and categories pertaining to the relevant subject matter and then re-read material relating to the codes and categories. In a second cycle of coding, informed by this close reading, I used the central concepts of this article - quality uncertainty, appraisal devices, competition, and assessorsto analyze the interview data. The writers expressed quality uncertainty when they said that they did not know whether they themselves and their work were any good. I identified them as referring to aspiration when they expressed a continued consistent course of action; that is, when they indicated a continued aspiration to become published. I coded for appraisal devices when they mentioned evaluations of cultural products and producers and, based on this coding, developed the concepts assessors and competitions. When the writers talked about using appraisal devices, they also talked about quality uncertainty and what happened to their aspiration after the appraisal. These coding procedures made it possible to analyze the links between the concepts and how they influenced each other.

\section{Assessors}

Assessors are trusted individuals whom the aspiring writers see as knowledgeable about how evaluations are made on the publishing market and who are able to produce such evaluations in a way that the aspiring writers trust. In reality, assessors may not be knowledgeable about evaluations in the publishing market or be able to effectually produce them, but writers may still use their appraisals as appraisal devices to determine their chances of success and failure on the publishing market. They do this because they trust the assessors, believe that the assessors are able to produce publishers' evaluations, and assume that the assessors are knowledgeable about the publishing market.

The most common assessor for the aspiring writer is a person who has become the writer's literary mentor. People become literary mentors to aspiring writers when they are able to guide them in their fiction writing and on the publishing market. The literary mentor and the writer come into contact through either a personal or a professional tie. A mentor with a personal tie might be a partner or friend who takes an interest in the person's writing. A mentor with a professional tie might be one who is hired for his or her writing services or who has a focused interest in the writer's abilities and creative work. Literary mentors are part of the writer's network and are seen as having professional knowledge and, therefore, belong to the network-market plus professional authority regime and are able to provide personalized knowledge about the writer's chances of success or failure.

Amelia is one of many writers I interviewed who had a literary mentor before getting published. She told me, 'My mentor sat with me twice in the fall and twice in the spring and went through the manuscript to make it publishable'. While working through the manuscript, the mentor indirectly gave appraisals about its chances for success and failure. Because the mentor was able to make the manuscript publishable, Amelia assumed that he had professional knowledge about the content of the manuscript and the publishing market and had mastered the matching logic that would determine how the manuscript would be evaluated on the publishing market. Amelia told me that it was not until the assessor had given his 'ready to go' that she felt sure enough to submit it, indicating that she felt a high degree of trust in the mentor's appraisals. Literary mentors, for their part, are often fully aware that they have the ability to discern quality and produce the evaluations of publishing houses. Billy is a published author who also acts as a literary mentor to aspiring writers and discussed this topic with me:

Often, I can have a pretty good idea about whether or not the manuscript is ready to be sent to the publishing houses. In some cases, I can say that this is guaranteed to be accepted. Sometimes I tend to say, 'Your manuscript is good enough to be accepted; now you need to have a little luck'. The manuscript needs to come to the right reader at the right publishing house at the right time. 
Billy saw himself as being able to evaluate manuscripts, and based on his experience with aspiring writers, he has learned what works and what does not. While publishers are cultural intermediaries whose taste defines what counts as good literature (Smith Maguire and Matthews, 2014), literary mentors act as stand-in cultural intermediaries for the publishers, as writers believe that mentors intuitively know about publishers' taste. By producing evaluations similar to those that publishers produce, assessors help conserve prevailing tastes and aesthetic hierarchies in the publishing market. This conservation of dominating aesthetics in the field also brings stability to prevailing power structures and interest. Hence, regardless of whether the source of evaluation is assessors or competitions, these evaluations are not neutral. Mentors can also help move aspiring artists into a favorable network position (Faulkner, 1983) and offer emotional support that helps artists build the emotional energy necessary to form an aspiration to succeed (Lee, 2016). But aspiring writers have learned to differentiate people who give them general emotional support from true, trusted, and knowledgeable assessors.

Cassandra knew this distinction and expressed sentiments typical for aspiring writers when she told me that she had 'literary mentors who read my work and whom I trust', which for her was distinct from having friends who offered her emotional support. People who give general support are often friends and relatives and are not usually engaged in the literary world in a professional way. Their comments are of a different nature; Cassandra said: 'You often get stupid comments from the ones you are close to. They do not get shit. When they see you, they usually say, "You are so good—come here and I'll give you a hug"“. Writers often seem to see appraisals from friends and family as partial and assume that friends and family are not knowledgeable about the publishing market, and they therefore do not trust them in that respect; friends and family cannot be subsumed under the network-market plus professional authority regime. Cassandra, however, came to know an established writer who had won several prestigious awards, suggesting that reputation matters not only when selecting cultural goods (Beckert and Rössel, 2013), but also when selecting a trustworthy assessor. She trusted this assessor's evaluations, appraisals, and ability to predict how her work would be evaluated on the publishing market; this information enabled her to determine the quality of her work from the perspective of the publishing houses and to eventually realize that it might be actually published in the future. Cassandra exemplifies writers' active search for an answer to how the quality of their manuscript would be evaluated on the publishing market as they search for information that is both personalized and professional about their manuscripts' chances on the publishing market and assume that a trusted and credible assessor has mastered the matching logic.

There is also a difference between evaluating a work in general and evaluating it in relation to how it will be evaluated on the publishing market. Ingrid, who used to aspire to be published, described what her literary mentor said: 'He said that this manuscript is really good, but it will not be published. It does not match any publisher'. The literary mentor introduces an important distinction in the work carried out by assessors: they are able to determine the quality of a literary work from several perspectives. Ingrid's mentor was able to determine the quality of the work from the publishing market and from another, different perspective. This means that an effective appraisal device is based on the perspective of the publishing market and not some other perspective. The manuscript's quality is constructed in relation to the perspective of publishers as the buying side of the publishing market. Writers learn about this distinction and try to discern whether their mentor is able to take the perspective of the publishing market and evaluate the writer's work according to the necessary matching logic.

Some writers actively avoid others' appraisals. Peter, for instance, said 'I kept my writing concealed from others because I was quite worried that it would be bad'. He went on to have his work published, but, before that happened, he told me he did not know or anticipate how his work would be evaluated on the publishing market. It has also been shown many times that authors learn to anticipate how their work will be evaluated on the publishing market by learning to produce the publishing houses' evaluations and appraise their own chances of success and failure (Svedjedal, 2000: 100-114). This skill is a consequence of getting to know the publishing market through mentors and other people's guidance, reading about how the publishing market works and, as I discuss below, partaking in competitions. By engaging 
in these activities, writers learn about how the publishing market works and come to believe that they are able to evaluate their work as it would be evaluated by publishing houses. This does not mean that they are correct in their evaluation, but if they believe and trust in the produced evaluation, that evaluation becomes an important way of dealing with quality uncertainty.

\section{Competitions}

Appraisals from competitions come about differently than appraisals from knowledgeable and trusted individuals acting as assessors. Assessors and writers have a one-to-one relationship in which assessors evaluate manuscripts and give their appraisals directly to writers. Competition, on the other hand, is based on a constellation of individuals who select and reject a large amount of material. These individuals deem the material to be either of the right quality to be selected or not, and they order the submitted work based on that judgment. The former is a substantial device that creates substantial knowledge about the quality of the creative work, and the latter is a formal device that uses the relative position of the creative work to create knowledge about relative quality. An appraisal from a competition only becomes an appraisal device if the writer believes that the evaluation carried out in the competition corresponds to how the publishing market will evaluate the writer's work in the future, thus conforming to the matching logic. This section analyzes three types of competitions that can serve as appraisal devices: writing school admissions, publications in journals, and rejections from publishing houses.

Danielle is a published writer who, like many other aspiring writers, applied for acceptance to a writing school. When she was accepted, she knew that 'it was a recognition just to have been accepted to the writing school'. She told me she wanted to attend the school to develop her writing abilities, finish her manuscript, and meet people in the literary world (as discussed by Childress and Gerber, 2015), but the admission itself became a sort of 'sign of approval'. This sign indicated to her not only that she could write good-quality literature, but also that her work could one day be published. This interpretation assumes that the people who evaluated her work at the writing school did so similarly to how her work would be evaluated on the publishing market in the future. In other words, she assumed that the school's admissions officers were experts whose appraisal conformed to an expert-opinion regime in which selection is based on criteria of excellence and originality, such that selection is a sign of being able to write good-quality literature. The result of experts' assessment is a rank order used as a formal device to signal the position of the individual work on a scale relative to others and is, therefore, impersonal. The writer, however, uses the rank order as if it were a personal device providing personalized and professional information about the prospects of the writers' work on the publishing market.

Jens's work had not been published, and he told me that he no longer aspired to publication. He had previously submitted his work to a writing school and had not been accepted. He used this appraisal as an appraisal device and began to doubt his ability to write fiction and question whether he would ever be published. In hindsight, he argued for a connection between this doubt and his 'starting doing things other than fiction writing'. He used the writing school's response as an appraisal of his ability in general and of whether or not his would one day be published. Like Jens, Kerstin had been rejected from writing school and said that she had been 'very disappointed when I was not accepted to the writing school'. Later on in her career, she considered whether this appraisal might be a signal of her chances for success and failure on the publishing market. Her work was eventually published, however, and this concern dissipated.

Competition is also a part of literary prize contests. A jury's selection process results in a rank order that determines which applicants get nothing, which are nominated for the prize, and which win prizes. During the prize ceremony, winners are usually asked what the prize means to them. One of few writers who have won a literary prize is Cassandra, who won the prize for one of her short stories. Cassandra said that during the prize ceremony, she had said that she 'wanted to write and dreamed about continuing to do it. I would write books'. She recalled knowing that winning the prize was not only prestigious but also meant that people in the literary world had appraised her work and discerned that she could write, and 
that had told her that that her work could one day be published. Winning a literary prize was a sign to her that she was seen as a 'promising writer', meaning that she could possibly develop a literary career that included published books. The literary prize became an appraisal device for her because she trusted that the jury's evaluation corresponded to how publishing houses would evaluate her work. Once again, the jury's impersonal ranking became a personal device based on professional knowledge with an assumed matching logic.

Another sign of being a 'promising writer' is having one's work published in a literary journal or magazine. Submissions to journals and or magazines are placed into competition, and the result, that determines selection and rejection, is a rank order. Ester told me that when a journal published her work, 'it was a very big thing for me then'. Like being admitted to a writing school and winning a literary prize (English, 2005), having one's work published in a journal or magazine (De Nooy, 2002) involves recognition and prestige. Yet another aspect of journal or magazine publication is that writers can use the editors' evaluation as an appraisal device of the chances for success or failure on the book publishing market. Ester told me that becoming published in a literary journal for the first time 'was really important' to her because publishing houses had already rejected her work several times. To Ester, the literary journal's selection of her work was a positive recognition of her ability to write, and she assumed that others in the literary world, including publishing houses, would see it similarly. This suggests that artists may still hope that they are 'good enough' to be selected in an artistic market in spite of appraisals telling them otherwise. New appraisals of their work may lead them to reassess their chances for success or failure in the artistic market. Fanny, whose work had also been published in literary journals, said she 'was not surprised that I got selected by a publishing house in the end. Because I had, for years before the publication of the book, been published in journals'. She told me that this experience increased her confidence in her writing and, because she assumed that publishing houses would evaluate her work in a similar fashion as the journals did, made her believe that her work would eventually be published by a publishing house.

Writers also use rejections from publishing houses to evaluate their chances of success and failure on the publishing market. Publishing houses decide which manuscripts to publish based on a competition whose outcome is a rank order from selection to different forms of rejections. Writers receive a response from the publishing house telling them whether their work has been selected or rejected, along with an appraisal of the author's chances of future success and failure in the publishing market. Writers typically see the publishing houses as knowledgeable and trust that their evaluations correspond to how the writer's work will be evaluated in the future and thereby conform to the matching logic.

Most responses from publishing houses are rejections. Nevertheless, these rejections carry different meanings. Writers learn about these different meanings by experiencing different kinds of rejection or by learning from others what the rejections mean. Hanna's work has been published, but like most aspiring writers, she received rejections earlier in her writing career. She told me that she had learned that publishing houses were interested in her work when she 'read the rejection letter. It was not this standard rejection letter: "We thank you for submitting your manuscript, but we are not interested in publishing your work"، Her rejection letters were more elaborate, she told me, and described the plot and what the editors liked and disliked about it. Like other writers, Hanna had learned that publishing houses usually respond with a standard rejection letter, so she interpreted this more engaged rejection as a signal that she was among the chosen few. Hanna used the rejection as an appraisal device to indicate that her work could be published in the future.

Writers can also use appraisals from journals, writing schools, and publishing houses as guideposts that indicate that their chances of success are not great and as cognitive support for making a reasonable decision about their aspirations. These 'momentous interactions' may also emotionally charge an aspirant to either sustain or dissipate an aspiration to success (Lee, 2016). Writers' responses to and use of appraisal devices are not mechanical but depend on how they interpret the appraisal and use it in the course of action. Ingrid, for example, told me about several years of struggle during which publishing houses were regularly rejecting her work. She vividly remembered reading her last rejection letter and realizing that her work would not be published in the future. She told me that she "then realized that the rejection letter contained a 
fundamental question and critique of my work and this critique was everywhere in the previous rejection letters. I got stuck. After this rejection letter I stopped sending manuscripts to publishing houses'. Ingrid learned to interpret the meaning of her rejection letters and came to see them as appraisals that indicated that her work might never be published. She trusted these evaluations and assumed that they mirrored her future chances for success, and she used the rejection as an appraisal device.

\section{Discussion}

Cultural production and careers in cultural industries are conditioned by quality uncertainty. Aspiring artists are torn between their aspiration and the uncertainty of not knowing whether their work is of the right quality to succeed in an artistic market. This article has focused on this tension amongst aspiring writers. It has argued that aspiring writers use appraisal devices to deal with the tension between their aspiration and the uncertainty of not knowing whether their work will be published by publishing houses on the publishing market. Appraisal devices thus reduce uncertainty about the quality of artists' work and how it will be evaluated on the artistic market in the future. But an appraisal is only used as an appraisal device when it comes from a source the artist trusts and sees as able to give an evaluation that corresponds to how the artists' work would be evaluated on the artistic market.

The concept appraisal device and the associated framework capture the handling of the consequences of market uncertainty for artists aspiring to succeed in artistic markets. This article presents two sources of appraisal devices: appraisers and competitions. Table 1 shows how appraisers and competitions relate to Karpik's framework of the economics of singularities. These two types of appraisal devices are both what Karpik (2010) calls personal devices, in contrast to impersonal devices. Impersonal devices produce knowledge that is available to a public, while personal devices are personalized knowledge brought about through personal relations. Both appraisers and competitions create personalized knowledge about the chances of success and failure on the artistic market. Karpik (2010: 100) also distinguishes between substantial and formal devices. Substantial devices are about the content of the singularity; they produce specific knowledge about the singularity. Formal devices are about relative positions of singularities. Assessors produce knowledge about the singularities, the producers' work, with respect of their chances of success and failure on the artistic market. Competitions are about the relative position of the singularity and produce knowledge through that positioning. This means that a fundamental distinction between the two appraisal devices is that an assessor is a substantial device, while a competition is a formal device.

The coordination regimes in use for the two appraisal devices are also different. The coordination regime in use during competitions is the expert-opinion regime. The coordination regime of assessors is the network-market plus professional authority regime. Originally, the expert-opinion regime evaluation is based on criteria of excellence and originality and results in a ranking. However, artists can imagine that such a ranking represents an evaluation based on what I call a matching logic; that is, they can imagine that the evaluation is similar to how their work would be evaluated on the publishing market and how the work matches with publishing houses. When an artist hires an assessor, the resulting appraisal device is based on a network-market that consists of friends and family (a personal network) along with buyers and sellers (a trade network). But they both blend into a network-market with professional authority regime, since the evaluation needs to be trusted and credible and the assessor must somehow be seen as a professional authority in the sense of knowing and being able to produce evaluations on the publishing market. Thus, as with competitions used as appraisal devices, the underlying logic for assessors as appraisal devices is a matching logic in which the artist's work is evaluated based on how well it would match with publishing houses. To use an appraisal as a device, artists need to be committed. They need to be actively searching out information about their chances of success or failure and, at the same time, rather than accepting their own tastes and evaluation, accepting the assessor's tastes and evaluation or the competition's ranking by a relation of heteronomy to the appraisal device. Table 1 summarizes this discussion. 
Table I. Dimensions of judgment devices applied to appraisal devices.

\begin{tabular}{lll}
\hline Source (relation to appraisal device) & Assessor & Competition \\
\hline Personal or impersonal device & Personal device & Personal device \\
Substantial or formal device & Substantial device & Formal device \\
Coordination regime & Network-market plus professional authority regime & Expert-opinion regime \\
Commitment & Active and heteronomy & Active and heteronomy \\
Logic & Matching logic & Matching logic \\
\hline
\end{tabular}

The concept of appraisal devices can be used to understand artists and their relationship to artistic markets in which they present and represent singularities of uncertain quality. The concept contributes to research on cultural production and creative industries, in which aspiring artists in particular have a hard time determining the quality of their work and their chances of success and failure on the artistic market. However, appraisal devices are not only important to aspiring artists. All artists' careers are imbued with aesthetic and quality uncertainty, and this uncertainty prevails throughout their careers (Menger, 2014). Further research on artists that have already succeeded once in the artistic market would enable us to understand additional kinds of appraisal devices, including evaluations of success on the artistic market — the artist's track record — and the reception of the artist and his or her work in the art world — for example, appraisals from critics.

Appraisal devices are not 'neutral' but part of producing and reproducing aesthetic hierarchies and judgments of taste in the artistic field. The politics of appraisal devices as a form of valuation that establishes the value of artistic works needs further exploration. Further research might also explore appraisal devices in contexts other than fiction writing and the publishing market. An example close to the present study is scholarly publishing, which involves both assessors, such as trusted, knowledgeable, and well-published scholars, and appraisals from competitions, including previous rejection letters. Research on appraisal devices should particularly address freelance and project-based careers (Faulkner and Anderson, 1987). Gatekeepers have a significant role in determining the future of such careers because they select and reject people and the work that the worker presents and represents to the gatekeeper. Appraisal devices could, in general, be useful for studying how people who aspire to become something, in a situation where there is a lack of clear evaluative standards, deal with their aspiration and uncertainty about whether their work is of the right quality to be accepted.

\section{Funding}

The authors disclosed receipt of the following financial support for the research, authorship, and/or publication of this article: This work was supported by the European Commission, European Research Council (ERC 263699CEV).

\section{References}

Akerlof GA (1970) The market for "lemons": Quality uncertainty and the market mechanism. The Quarterly Journal of Economics 84(3): 488-500.

Anheier HK and Gerhards J (1991) Literary myths and social structure. Social Forces 69(3): 811-830. Barley SR (1989) Careers, identities, and institutions: The legacy of the Chicago School of Sociology. In: Arthur MB, Hall DT and Lawrence BS (eds) Handbook of Career Theory. Cambridge: Cambridge University Press, pp.41-65.

Beckert J (2016) Imagined Futures: Fictional Expectations and Capitalist Dynamics. Cambridge: Harvard University Press.

Beckert J and Rössel J (2013) The price of art. European Societies 15(2): 178-195. 
Bourdieu P (2000) The biographical illusion. In: Du Gay P, Evans J and Redman P (eds) Identity: A Reader. Los Angeles, CA: SAGE, pp.297-303.

Caves RE (2000) Creative Industries: Contracts Between Art and Commerce. Cambridge: Harvard University Press.

Cheshire C and Cook KS (2004) The emergence of trust networks under uncertainty: Implications for Internet interactions. Analyse \& Kritik 26(1): 220-240.

Childress CC and Gerber A (2015) The MFA in creative writing: The uses of a "useless" credential. Professions and Professionalism 5(2): 1-16.

Cint (2010) Swedish writing habits. Report prepared by Cint AB for Books on Demand. Unpublished report.

Dahlgreen W (2015) Bookish Britain: Literary jobs are the most desirable. Available at: https://yougov. co.uk/news/2015/02/15/bookish-britain-academic-jobs-are-most-desired/ (accessed 23 October 2017).

Dekker E (2016) Exemplary goods: Exemplars as judgment devices. Valuation Studies 4(2): 103-124.

De Nooy W (1991) Social networks and classification in literature. Poetics 20(5-6): 507-537.

De Nooy W (2002) The dynamics of artistic prestige. Poetics 30(3): 147-167.

DiMaggio P and Louch H (1998) Socially embedded consumer transactions: For what kinds of purchases do people most often use networks? American Sociological Review 63(5): 619-637.

Ekelund BG and Börjesson M (2002) The shape of the literary career: An analysis of publishing trajectories. Poetics 30(5-6): 341-364.

Ekelund BG and Börjesson M (2005) Comparing literary worlds: An analysis of the spaces of fictional universes in the work of two US prose fiction debut cohorts, 1940 and 1955. Poetics 33(5-6): 343-368.

English JF (2005) The Economy of Prestige: Prizes, Awards, and the Circulation of Cultural Value. Cambridge: Harvard University Press.

Faulkner RR (1983) Music on Demand: Composers and Careers in the Hollywood Film Industry. New Brunswick, NJ: Transaction Books.

Faulkner RR and Anderson AB (1987) Short-term projects and emergent careers: Evidence from Hollywood. American Journal of Sociology 92(4): 879-909.

Janssen S (1998) Side-roads to success: The effect of sideline activities on the status of writers. Poetics 25(5): 265-280.

Kairos Future (2013) Svenska drömjobbet 2013: Rapport baserad på resultaten från Manpower Worklife. Available at: http://www.mynewsdesk.com/se/manpower/documents/download/resource_docu ment/30503 (accessed 23 October 2017).

Karpik L (2010) Valuing the Unique: The Economics of Singularities. Princeton, NJ: Princeton University Press.

Knight FH (1921) Risk, Uncertainty and Profit. Boston, MA: Houghton Mifflin.

Lamont M and Swidler A (2014) Methodological pluralism and the possibilities and limits of interviewing. Qualitative Sociology 37(2): 153-171.

Lahire B (2010) The double life of writers. New Literary History 41(2): 443-465.

Lee J (2016) Blowin' Up: Rap Dreams in South Central. Chicago, IL: University of Chicago Press.

McRobbie A (2016) Be Creative: Making a Living in the New Culture Industries. Cambridge: Polity Press.

Martin JL (2010) Life's a beach but you're an ant, and other unwelcome news for the sociology of culture. Poetics 38(2): 229-244. 
Mears A (2011) Pricing Beauty: The Making of a Fashion Model. Berkeley, CA: University of California Press.

Menger P-M (1999) Artistic labor markets and careers. Annual Review of Sociology 25: 541-574.

Menger P-M (2014) The Economics of Creativity: Art and Achievement Under Uncertainty. Cambridge: Harvard University Press.

Pugh AJ (2013) What good are interviews for thinking about culture? Demystifying interpretive analysis. American Journal of Cultural Sociology 1(1): 42-68.

Smith Maguire J and Matthews J (2014) The Cultural Intermediaries Reader. Los Angeles, CA: SAGE.

Stoyanova D and Grugulis I (2012) Tournament careers: Working in UK television. In: Mathieu C (ed) Careers in Creative Industries. New York: Routledge, pp.88-106.

Svedjedal J (2000) The Literary Web: Literature and Publishing in the Age of Digital Production: A Study in the Sociology of Literature. Stockholm: Kungliga Biblioteket.

Thompson JB (2012) Merchants of Culture: The Publishing Business in the Twenty-First Century. Cambridge: Polity Press.

Vaisey S (2009) Motivation and justification: A dual-process model of culture in action. American Journal of Sociology 114(6): 1675-1715.

Van Dijk N (1999) Neither the top nor the literary fringe: The careers and reputations of middle group authors. Poetics 26(5-6): 405-421.

Van Rees K and Vermunt J (1996) Event history analysis of authors' reputation: Effects of critics' attention on debutants' careers. Poetics 23(5): 317-333.

Zuckerman EW, Kim T, Ukanwa K, et al. (2003) Robust identities or nonentities: Typecasting in the feature film labor market. American Journal of Sociology 108(5): 1018-1073.

\section{Author biography}

Henrik Fürst obtained his $\mathrm{PhD}$ in Sociology from Uppsala University in 2017. He is currently studying cultural production, specifically the impact of quality uncertainty on the operation of artists and gatekeepers on artistic markets. In his dissertation, he focused on quality uncertainty in the Swedish publishing market and how it is handled by both aspiring writers and publishers. 